\title{
Program Kampung Literasi dalam Menumbuhkan Minat Baca Siswa SD/MI Desa Pandulangan Hulu Sungai Selatan
}

\author{
Muhammad Iqbal Ansari ${ }^{1}$, Nor Saidah ${ }^{2}$, Jumiati ${ }^{3}$ \\ 123 Islamic University of Kalimantan Muhammad Arsyad Al Banjari Banjarmasin , Indonesia
}

\begin{tabular}{|c|c|}
\hline \multicolumn{2}{|l|}{ (A) check for updates open $\widehat{A}_{\text {Access }}$} \\
\hline \multicolumn{2}{|r|}{ DOI : 10.47400/jiees.v.1i2.17 } \\
\hline Sections Info & \multirow{16}{*}{$\begin{array}{l}\text { ABSTRACT } \\
\text { This study aims to describe the implementation of the Kampung Literasi program in } \\
\text { Subdistrict and to describe the inhibiting and supporting factors of the Kampung } \\
\text { Literasi Program in Pandulang Village. This research uses a case study method with a } \\
\text { qualitative approach. This research uses observation, interview, and documentation to } \\
\text { collect the data. The data analysis technique used in this research is analysis of } \\
\text { qualitative data, data reduction, data presentation, and conclusion. Test the validity of } \\
\text { the data in this study using triangulation. Triangulation in credibility testing is } \\
\text { defined as checking data from various ways and at various times. Based on the results } \\
\text { of the study, it can be concluded that the Kampung Literasi program is running well } \\
\text { and that students frequently visit every Friday because every Friday morning there is } \\
\text { a visit from the Library and Archives Office of Hulu Sungai Selatan Regency in the } \\
\text { form of a reading park car and smart motorbikes. The inhibiting factors for the the } \\
\text { Kampung Literasi program in Pandulang village were students' lack of motivation } \\
\text { towards reading interest, inadequate space, and weather factors. Meanwhile, the } \\
\text { supporting factors for the Literacy Village program in Pandulang village were } \\
\text { facilities and infrastructure, the availability of reading materials and government } \\
\text { support. }\end{array}$} \\
\hline Article history: & \\
\hline Received: Oktober 082020 & \\
\hline Accepted: Oktober 102020 & \\
\hline Published online: Desember 30 & \\
\hline 2020 & \\
\hline Keywords: & \\
\hline Literacy Village & \\
\hline Interest in Reading & \\
\hline & \\
\hline & \\
\hline & \\
\hline & \\
\hline & \\
\hline & \\
\hline & \\
\hline
\end{tabular}

\section{INTRODUCTION}

Indonesia merupakan negara yang memiliki sumber daya manusia (SDM) dan sumber daya alam (SDA) yang melimpah. Dengan potensi besar ini, Indonesia mampu menjadi bagian negara maju di dunia. Namun, sampai saat ini Indonesia masih termasuk dalam kategori negara berkembang yang terus berupaya membebaskan diri dari sejumlah masalah domestik, terutama terkait dengan peningkatan kualitas SDM. Masalah kualitas SDM tersebut berpotensi menghambat kemajuan Indonesia. Pendidikan menjadi prioritas utama dalam upaya membangun dan meningkatkan kualitas manusia. Dalam upaya ini diperlukan sarana dan prasarana serta kemauan dan kesiapan setiap individu maupun kelompok untuk berpikir maju dan mengembangkan kompetensi diri.

Peningkatan kualitas manusia melalui pendidikan, berkaitan erat dengan tingkat minat baca. Hasil survei beberapa lembaga menunjukkan tingkat minat baca masyarakat Indonesia masih rendah. Bahkan di bawah rata-rata tingkat minat baca negara Asia lainnya. Penelitian United Nations Educational, Scientific and Cultural Organization (UNESCOO tahun 2016 memperlihatkan indeks tingkat baca Indonesia hanya 0,001 persen yakni hanya satu dari 1000 penduduk Indonesia yang memiliki 
JIEES : Journal of Islamic Education at Elementary School Homepage : http://jiees.alkhoziny.ac.id/index.php/jeies Email : jiees@alkhoziny.ac.id
p-ISSN : 2723 -7184; e-ISSN : 2723-8148 JIEES, Vol. 1, No.2, Desember $2020: 60-72$

(C) 2020 JIEES : Journal of Islamic Education at Education School

minat baca tinggi. Hasil ini menempatkan Indonesia pada posisi 124 dari 187 negara pada penilaian Indeks Pembangunan Manusia (IPM). (Puspen Kemendagri, 2020)

Data yang menggembirakan adalah capaian pemberantasan buta aksara di Indonesia. Hasil sensus Badan Pusat Statistik (BPS) tahun 2018 jumlah penduduk buta aksara turun menjadi 3,29 juta orang atau hanya 1,93\% dari total populasi penduduk. Pada tahun 2017, jumlah penduduk buta aksara tercatat 3,4 juta orang. Dengan berbagai program pemberantasan buta aksara yang dilakukan Kementerian Pendidikan dan Kebudayaan (Kemendikbud), angka buta aksara ini mengalami penurunan yang sangat signifikan dibandingkan tahun-tahun sebelumnya. (Kemendikbud:2019)

Data minat baca dan tingkat buta aksara tersebut berpengaruh terhadap posisi Human Development Index (HDI) Indonesia. HDI berkaitan dengan Indeks Pembangunan Manusia (IPM) yang diukur dari usia harapan hidup (tingkat kesehatan), pertumbuhan ekonomi dan kualitas pendidikan. HDI Indonesia di tahun 2019 berada di peringkat ke-111 dari 189 negara. Angka HDI ini menunjukkan bahwa Indonesia juga berada jauh di bawah sejumlah negara di ASEAN. Hasil-hasil survei tersebut menunjukkan gentingnya persoalan minat baca dan literasi di Indonesia. Sebagai negara dengan jumlah penduduk mencapai 270.234.842 jiwa, peringkat ke-4 dari segi jumlah penduduk terbanyak di dunia, dari segi minat baca dan HDI Indonesia jauh tertinggal dibandingkan negara lain. Berbekal pengalaman dalam pemberantasan buta aksara, bukan hal yang mustahil jika kita secara bersama-sama dan berupaya melakukan berbagai hal bahkan yang out of the box, kita bisa meningkatkan minat baca dan literasi masyarakat.(Dirjen PAUD dan Dikmas, 2017)

Berdasarkan fakta tersebut, Pemerintah melalui Direktorat Pembinaan Pendidikan Keaksaraan dan Kesetaraan (Dit. Bindiktara), Ditjen PAUD Dikmas Kemendikbud, mengembangkan model pembelajaran non-formal yang komprehensif, yaitu dengan penyelenggaraan program Kampung Literasi. Program Kampung Literasi diharapkan menjadi poros pendidikan non-formal masyarakat yang tidak hanya mengajarkan membaca, menulis dan berhitung (calistung), namun juga menjadi salah satu solusi dalam mengatasi problematika rendahnya pengetahuan dan minat baca masyarakat. Kampung Literasi dikembangkan agar masyarakat, memiliki 6 kecakapan literasi, yaitu literasi baca tulis, literasi berhitung, literasi sains, literasi teknologi informasi dan komunikasi (TIK), literasi keuangan serta literasi budaya dan kewarganegaraan.

Siswa sekolah dasar berada pada rentangan tahapan operasional konkret. Masa ini merupakan masa perkembangan anak yang penting. Oleh karena itu, pada masa ini potensi yang dimiliki anak perlu dikembangkan. Perkembangan siswa yang perlu diperhatikan adalah pendidikan bahasa dan kemahiran literasi. Pendidikan literasi merupakan salah satu aspek penting yang harus diterapkan guna memupuk minat dan bakat dalam diri peserta didik sejak usia dini. (Ariyani \& Apriani, 2015) Literasi merupakan salah satu aktifitas penting dalam hidup. Sebagian besar proses pendidikan bergantung pada kemampuan dan kesadaran literasi. Budaya literasi yang tertanam dalam diri peserta didik mempengaruhi tingkat keberhasilan dan kemampuan peserta didik untuk memahami informasi secara analitiss, kritis, dan reflektif 
JIEES : Journal of Islamic Education at Elementary School Homepage : http://jiees.alkhoziny.ac.id/index.php/jeies Email : jiees@alkhoziny.ac.id
p-ISSN : 2723 -7184; e-ISSN : 2723-8148 JIEES, Vol. 1, No.2, Desember $2020: 60-72$

(C) 2020 JIEES : Journal of Islamic Education at Education School

Guna mencapai tujuan tersebut, maka dilakukan pembinaan minat baca pada siswa sekolah dasar. Dengan membaca akan mengatahui informasi dan menambah ilmu pengetahuan, akan tetapi membangun kebiasaan membaca bukan hal mudah apalagi pada era digital sekarang ini dimana informasi dapat diakses oleh siapa saja, dimanapun dan kapanpun, tetapi siswa lebih sering menggunakannya untuk sosial media dan bermain game daripada membaca dan mencari informasi.

Pembinaan minat baca merupakan proses yang penting untuk menumbuhkan dan mengembangkan minat baca pada siswa karena membaca merupakan kegiatan paling dasar dan merupakan suatu keterampilan serta kebiasaan yang penting dalam kegiatan sehari-hari. Dalam hal meningkatkan minat baca, pada tanggal 1 Desember 2018 Pemerintah melalui Dinas Pendidikan Kabupaten Hulu Sungai Selatan menggelar pencanangan Gerakan Indonesia Membaca (GIM) dan menetapakan Desa Pandulangan Kecamatan Padang Batung sebagai Kampung Literasi yang bekerja sama dengan Dinas Perpustakaan dan Kearsipan Kabupaten Hulu Sungai Selatan untuk menyediakan bahan bacaan yang bermutu, sesuai kebutuhan siswa dan terus melakukan upayaupaya inovatif lainnya untuk mendorong dan memperkokoh budaya membaca. Karena dengan keterampilan literasi yang baik akan membantu siswa dalam memahami teks lisan, tulisan, maupun gambar/visual.

Hasil observasi menunjukkan bahwa di desa Pandulangan terdapat 2 sekolah dasar, yaitu SDN Pandulangan dan MIS Al-Husna Pandulangan. Dengan adanya program Kampung Literasi, pihak sekolah memanfaatkannya untuk meningkatkan kemampuan literasi para siswa. Kedua sekolah tersebut mengunjungi Kampung Literasi setiap jumat secara bergantian dengan dua gelombang, yaitu minggu pertama untuk kelas rendah dan minggu selanjutkan untuk kelas tinggi. kegiatan Kampung Literasi di desa Pandulangan dilaksanakan setiap hari. Namun waktu yang sering mendapat kunjungan adalah pagi hari jumat, karena pada hari tersebut akan ada kunjungan mobil Taman Bacaan Masyarakat (TBM) dan motor pintar membawa bahan bacaan yang berbeda-beda tiap minggu dari Dinas Perpustakaan dan Kearsipan Kabupaten Hulu Sungai Selatan.

Berdasarkan hasil wawancara dengan Kepala Sekolah di kedua sekolah dasar tersebut didapati bahwa pihak sekolah sangat terbantu dengan adanya program Kampung Literasi, karena secara tidak langsung membantu menambah bahan bacaan bagi siswa. Selain itu, program ini juga menjadi ajang "kompetesi' para siswa agar saling berlomba dalam membaca, karena mereka akan berkumpul dengan kawankawan lintas kelas, bahkan lintas sekolah.

Berdasarkan uraian di atas penulis tertarik meneliti program Kampung Literasi dalam menumbuhkan minat baca siswa sekolah dasar Desa Pandulangan Kecamatan Padang Batung kabupaten Hulu Sungai Selatan. Penelitian ini diharapkan dapat memberikan gambaran tentang program Kampung Literasi dalam meningkatkan minat baca siswa sekolah dasar di sana. 
JIEES : Journal of Islamic Education at Elementary School Homepage : http://jiees.alkhoziny.ac.id/index.php/jeies Email : jiees@alkhoziny.ac.id
p-ISSN : 2723 -7184; e-ISSN : 2723-8148 JIEES, Vol. 1, No.2, Desember $2020: 60-72$

(C) 2020 JIEES : Journal of Islamic Education at Education School

\section{RESEARCH METHOD}

Penelitian ini dilakukan di Kampung Literasi yang beralamat di Jalan Tanayung, RT. 002 RW.002 Desa Pandulangan Kecamatan Padang Batung Kabupaten Hulu Sungai Selatan. Penelitian ini dilakukan kurang lebih 3 (tiga) bulan di awal tahun 2020. Peneliti melaksanakan wawancara dengan pengelola program Kampung Literasi, wali kelas, siswa. Pengumpulan data melalui observasi dilakukan sebelum Pandemi COVID-19 merambah Indonesia. Selanjutnya ketika memasuki pandemi, peneliti fokus pada melaksanakan wawancara dengan pihak perpustakaan pengelola motor pintar dan mobil Taman Bacaan Masyarakat (TBM), pengelola program Kampung Literasi dan siswa yang berkunjung ke Kampung Literasi.

Penelitian ini menggunakan pendekatan kualitatif. Menurut Bogdan \& Biklen yang dikutip oleh Ansari bahwa metode kualitatif merupakan salah satu prosesur penelitian yang menghasilkan data deskriptif berupa kata-kata tertulis atau lisan dari orang-orang dan perilaku yang dapat diamati dan diarahkan pada latar dan individu secara utuh. Tujuan penelitian kualitatif adalah mencari dan memperoleh informasi mendalam. (Ansari \& Barsihanor, 2018)

Menurut Hamid (2013:2-3) pendekatan kualitatif dikenal mempunyai bermacam nama dalam beberapa ilmu. Antropologi menamakan etnografi kepada pendekatan kualitatif, sosiologi menyebutkan versthen atau pengamatan terlibat, psikologi dengan folklore, lingustik, etnomuskologi, etnometodologi, dan banyak disiplin ilmu lainnya, menggunakan istilah-istilah seperti studi kasus, interpretative inquiry, natural inquiry, dan phenomenology sebagai sebutan dari pendekatan kualitatif. John $W$. Creswell mendefiniskan pendekatan kualitatif sebagai sebuah proses penyelledikan untuk memahami masalah social atau masalah manusia berdasarkan pada pencioptaan gambar holistic yang dibentuk dengan kata-kata, melaporkan pandangan informasi secara terinci, dan disusun dalam sebuah latar ilmiah.

Karena rencana penelitian ini adalah studi kasus. Menurut Ghonydan Fauzan yang dikutip Ansari bahwa Studi Kasus (case study) merupakanpenelitian tentang sesuatu "kesatuan sistem." Kesatuan ini dapat berupa program,kegiatan, peristiwa, atau sekelompok individu yang terkait oleh tempat, waktu, dan ikatan tertentu. (Ansari, 2019) Penelitan ini menggunakan Studi Kasus Prospektif (Prospective Case Study), yaitu studi kasus ke arah perkembangan yang positif. Jenis studi kasus ini digunakan untuk menemukan kecenderungan dan arah.(Ansari \& Barsihanor, 2018)

Sumber data berupa data primer dan data sekunder, sumber data primer yang dipilih dalam penelitian ini yaitu: narasumber (informan), peristiwa atau aktivitas, tempat atau lokasi. (Ansari, 2016) Data penelitian ini dikumpulkan berupa informasi tentang program Kampung Literasi dalam meningkatkan minat baca. Data penelitian itu dikumpulkan dari berbagai sumber seperti wawancara dengan pengelola program Kampung Literasi, guru atau wali kelas yang mendampingi ke Kampung Literasi, pihak perpustakaan yang membawa motor pintar dan mobil Taman Bacaan Masyarakat (TBM), dan siswa yang berkunjung ke Kampung Literasi tersebut. Dokumentasi berupa jadwal kegiatan di Kampung Literasi, foto kegiatan di Kampung Literasi, dan daftar 
JIEES : Journal of Islamic Education at Elementary School Homepage : http://jiees.alkhoziny.ac.id/index.php/jeies Email : jiees@alkhoziny.ac.id
p-ISSN : 2723 -7184; e-ISSN : 2723-8148 JIEES, Vol. 1, No.2, Desember $2020: 60-72$

(C) 2020 JIEES : Journal of Islamic Education at Education School

kunjungan Kampung Literasi. Observasi langsung ke lapangan untuk melihatan keadaan dan situasi di Kampung Literasi.

Menurut Hamid (2013:100) mengutip dari Matthew dan Michael bahwa data itu telah dikumpulkan dalam aneka macam cara yaitu pengamatan terlibat, wawancara semi terstruktur, dan selanjutnya diproses melalui perekaman, pencatatan, pengetikan, tetapi analisis kualitatif tetap menggunakan kata-kata yang biasanya disusun ke dalam teks yang diperluas. Analisis data ini bertujuan untuk mengatahui program Kampung Literasi dalam meningkatkan minat baca siswa sekolah dasar yang ada di desa Pandulangan kecamatan Padang Batung kabupaten Hulu Sungai Selatan. Adapun teknik analisis data yang digunakan pada penelitian ini adalah analisis data kualitatif, meliputi reduksi data, penyajian data, dan penarikan kesimpulan. Untuk memahami analisi data tersebut, maka akan dijelaskan sebagai berikut:

Menurut Sugiyono (2017:184) uji keabsahan data dalam penelitian kualitatif meliputi uji credibility (validitas internal), trasferbility (validitas eksternal), dependability (reliabilitas), dan confirmability (objektivitas). Dalam penelitian ini untuk menguji keabsahan data, peneliti menggunakan uji kredibilitas. Dalam pengujian kredibilitas penelitian ini, peneliti menggunakan triangulasi, yaitu triangulasi teknik, waktu, dan sumber.

\section{RESULTS AND DISCUSSION}

Program Kampung Literasi dicanangkan pada tanggal 1 Desember 2018. Layanan program Kampung Literasi buka setiap hari dari pukul 08.00-12.00 WITA. Program ini diselenggarakan oleh Pusat Kegiatan Belajar Masyarakat (PKBM) serumpun adalah salah satu lembaga yang di desa Pandulangan yang didirikan tanggal 26 juni 1999 dan sudah terakreditas B. PKBM serumpun mempunyai program-program yang dilaksanakan setiap hari. Program-program yang ada di PKBM serumpun ialah sekolah paket B dan C, taman bacaan masyarakat, dan program Kampung Literasi. Penelitian ini tentang program Kampung Literasi.

\section{Program Kampung Literasi di Desa Pandulangan Kecamatan Padang Batung} dilaksanakan 2 tahap, yaitu perencanaan dan pelaksanaan.

Pada tahap perencanaan, program Kampung Literasi di Desa Pandulangan telah direncanakan dengan sangat matang, hal itu dilihat dari proses serta susunan kegiatan yang telah dibuat serta adanya dukungan dari pemerintah pada saat pencanangan program Kampung Literasi tanggal 1 Desember 2018 yang diresmikan langsung oleh Bupati Hulu Sungai Selatan. Penyelenggara program Kampung Literasi dilakukan oleh PKBM Serumpun Desa Pandulangan karena syarat melaksanakan program Kampung Literasi lembaga atau TBM adalah sudah terakreditasi minimal B. Salah 1 syarat meraih Akreditasi B ialah bahwa Ketua PKBM harus berpendidikan minimal strata-1.

Awal pembahasan untuk melaksanakan program Kampung Literasi ialah dengan mengadakan koordinasi melalui rapat bersama masyarakat di desa Pandulangan guna membahas lokasi program, pengelola, dan jadwal kegiatan. Langkah selanjutnya membuat proposal yang ditujukan ke Dinas Pendidikan 
JIEES : Journal of Islamic Education at Elementary School Homepage : http://jiees.alkhoziny.ac.id/index.php/jeies Email : jiees@alkhoziny.ac.id
p-ISSN : 2723 -7184; e-ISSN : 2723-8148 JIEES, Vol. 1, No.2, Desember $2020: 60-72$

(C) 2020 JIEES : Journal of Islamic Education at Education School

Kabupaten Hulu Sungai Selatan untuk mendapatkan rekomendasi menjalankan program Kampung Literasi, yang kemudian rekomendasi tersebut diserahkan ke Kementerian Pendidikan dan Kebudayaan, Direkturat Jendral Pendidikan Anak Usia Dini dan Pendidikan Masyarakat, Direkturat Pembinaan Pendidikan Keaksaraan dan Kesetaraan.

Program Kampung Literasi ini sejalan dengan program pemerintah Kabupaten Hulu Sungai Selatan seperti saat pencanangan program Kampung Literasi yang diungkapkan oleh Bapak Nordiansyah S.Sos M.Si selaku Kepala Dinas Pendidikan Kabupaten Hulu Sungai Selatan program Kampung Literasi sejalan dengan salah satu program unggulan pemerintah Kabupaten Hulu Sungai Selatan dalam RPJMD 20182023 yakni program peningkatan budaya baca.

Program Kampung Literasi sebenarnya mencakup 6 literasi yaitu literasi baca tulis, literasi berhitung, literasi sains, literasi keuangan, literasai digital, dan literasai budaya\&kewargaan. Namun di kampung literasi Desa Pandulangan hanya melaksanakan 4 program literasi yaitu literasi baca tulis, literasi berhitung, literasi digital, dan literasi budaya\&kewargaan. Hal ini karena fasilitas yang belum mendukung untuk mengadakn literasi sains dan literasi keuangan. Pelaksanaa 4 program literasi ini sudah memenuhi syarat operasional, karena minimal harus melaksanakan 2 dari 6 program literasi.

\section{Adapun pelaksanaan Program Kampung Literasi Desa Pandulangan Kecamatan \\ Padang Batung dalam rangka meningkatkan minat baca siswa sekolah dasar berjalan dengan baik sesuai perencanaan yang disusun.}

Hasil observasi di lapangan kegiatan Kampung Literasi Desa Pandulangan dibuka setiap hari, dengan rincian hari Senin-Kamis dari pukul 08.00-12.00 WITA, hari Jum'at pukul 08.00-11.00 WITA, sedangkan hari Sabtu dan Minggu pukul 08.00-12.00 WITA tapi yang sering di dikunjungi hari jumat pagi karena pada hari tersebut ada kunjungan dari Dinas Perpustakaan dan Kearsipan Kabupaten Hulu Sungai Selatan berupa mobil Taman Bacaan Masyarakat (TBM) dan motor pintar membawa bahan bacaan yang berbeda-beda tiap minggu. Di Desa Pandulangan ada 2 buah sekolah dasar, yaitu SDN Pandulangan dan MIS Al-Husna Pandulangan. Kedua sekolah tersebut mengunjungi kampung literasi setiap Jumat secara bergantian dengan dua gelombang yaitu minggu pertama untuk kelas rendah dan minggu selanjutkan untuk kelas tinggi.

Kampung Literasi secara sosial memberikan dampak yang positif bagi siswa, karena di tempat tersebut siswa akan berkumpul dan bersosialisasi dengan teman sebayanya, baik itu antar lintas kelas maupun lintas sekolah, sehingga terjadi persaingan akademik yang baik. Berbeda dengan pembelajaran secara daring yang saat ini harus dialami oleh para siswa. Berdasarkan hasil penelitian Risalah, dkk bahwa pembelajaran daring menimbulkan sikap anti sosial karena memilih untuk bermain gadget. Tingkat kerajinan anak menjadi menurun seperti bangun lebih siang. (Ainur Risalah et al., 2020) 


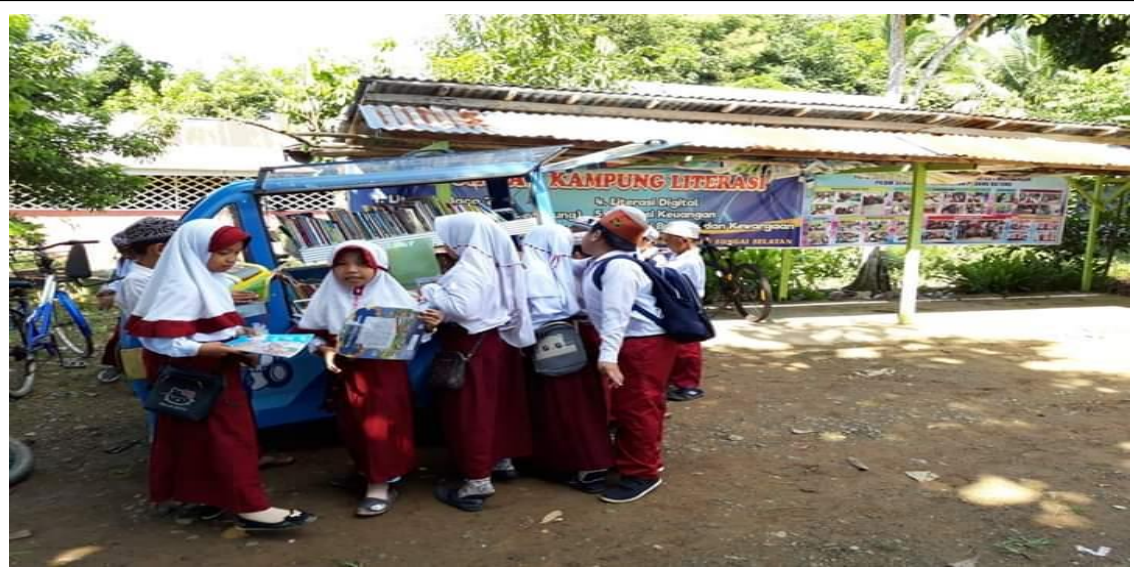

Gambar 1: Siswa Mengantri Mengambil Buku di Motor Pintar

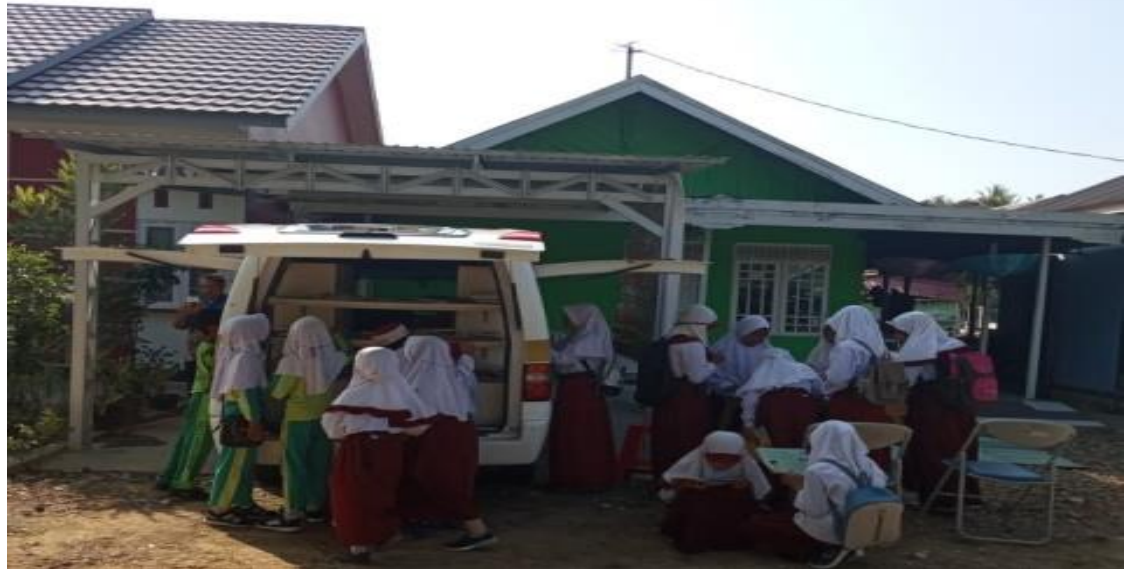

Gambar 2: Siswa Memilih Buku di Mobil Taman Bacaan Masyarakat (TBM)

Selain kunjungan dari Dinas Perpustakaan dan Kearsipan daerah Kabupaten Hulu Sungai Selatan program kampung literasi juga melaksanakan evaluasi berupa lombalomba dalam meningkatkan minat baca untuk memperingati hari-hari nasional seperti pada tahun baru islam 1 Muharam $1441 \mathrm{H}$ mengadakan lomba dengan tema mengenang sejarah kelahiran Nabi Muhammad Saw. Lomba yang dilaksanakan adalah lomba bercerita, membuat pantun, baca puisi, dan membaca cepat. Diharapkan dengan adanya lomba-lomba siswa semakin giat berliterasi dengan memanfaatkan program Kampung Literasi.

Kegiatan lomba bercerita, sebagaimana penelitian Permatasari, $d k k$ bahwa bercerita sebagai salah satu bentuk kegiatan literasi berfungsi untuk memancing kemampuan dan kreativitas siswa. (Permatasari et al., 2017) Ditambah lagi jika bercerita dilombakan dan pemenangnya akan mendapatkan hadiah, sehingga memantik motivasi siswa untuk lebih bersiap-siap dengan cara membaca buku dengan tekun.

Lomba berikutnya yang dilaksanakan adalah lomba pantun dan puisi. Amalia, dkk dalam penelitiannya memaparkan bahwa pantun merupakan karya asli bangsa Indonesia tentu memiliki nilai-nilai filosofis, dan budaya yang "adi luhung". Nilai "adi 
JIEES : Journal of Islamic Education at Elementary School Homepage : http://jiees.alkhoziny.ac.id/index.php/jeies Email : jiees@alkhoziny.ac.id
p-ISSN : 2723 -7184 ; e-ISSN : 2723-8148 JIEES, Vol. 1, No.2, Desember 2020 : 60-72

(C) 2020 JIEES :

Journal of Islamic Education at Education School

luhung" yang merupakan nilai-nilai kearifan ini yang harus dipelajari oleh siswa sehingga pantun memberikan konstribusi positif dalam membangun karakter siswa.(Amalia et al., 2018) Lomba pantun dan puisi bukan hanya meningkatkan kualitas literasi siswa, namun juga menjadi ajang kreatifitas siswa dalam menghibur penonton melalui rangkaian kalimat pantun yang jenaka atau berisi puisi rayuan pujangga.

Berdasarkan data di atas, pemilihan lomba oleh panitia merupakan cabang lomba yang memotivasi siswa untuk meningkatkan intensitas kegiatan literasi mereka, baik itu di rumah maupun di sekolah dengan memanfaatkan peminjaman buku dari Kampung Literasi.

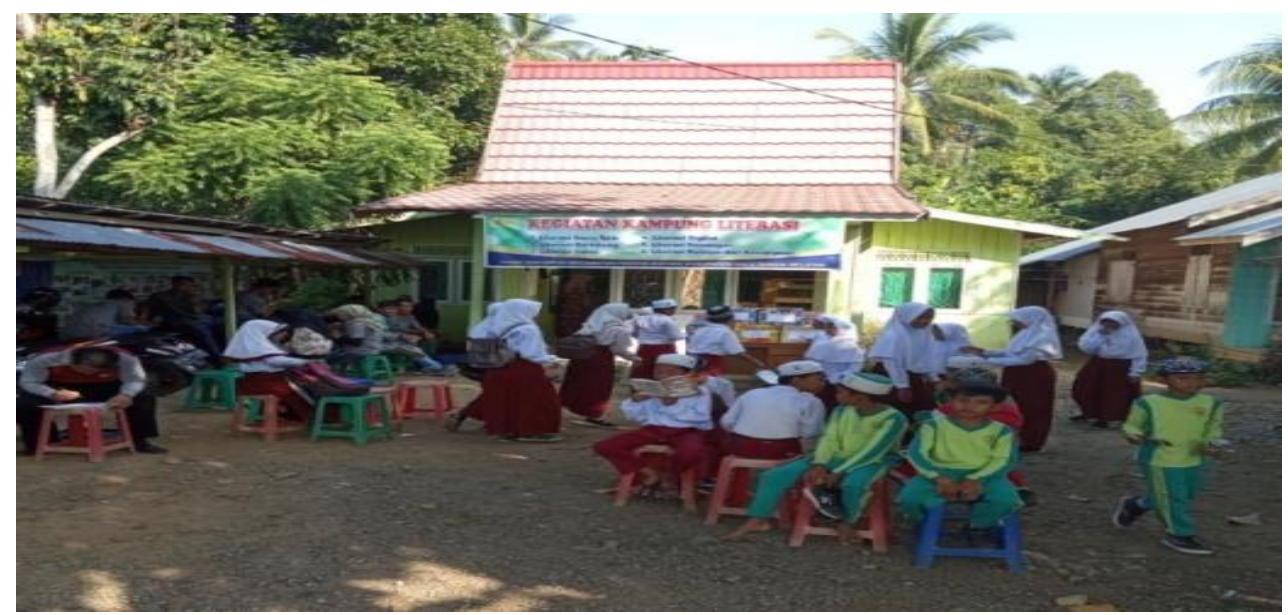

Gambar 3: Siswa Melakukan Registrasi untuk Mengikuti Lomba

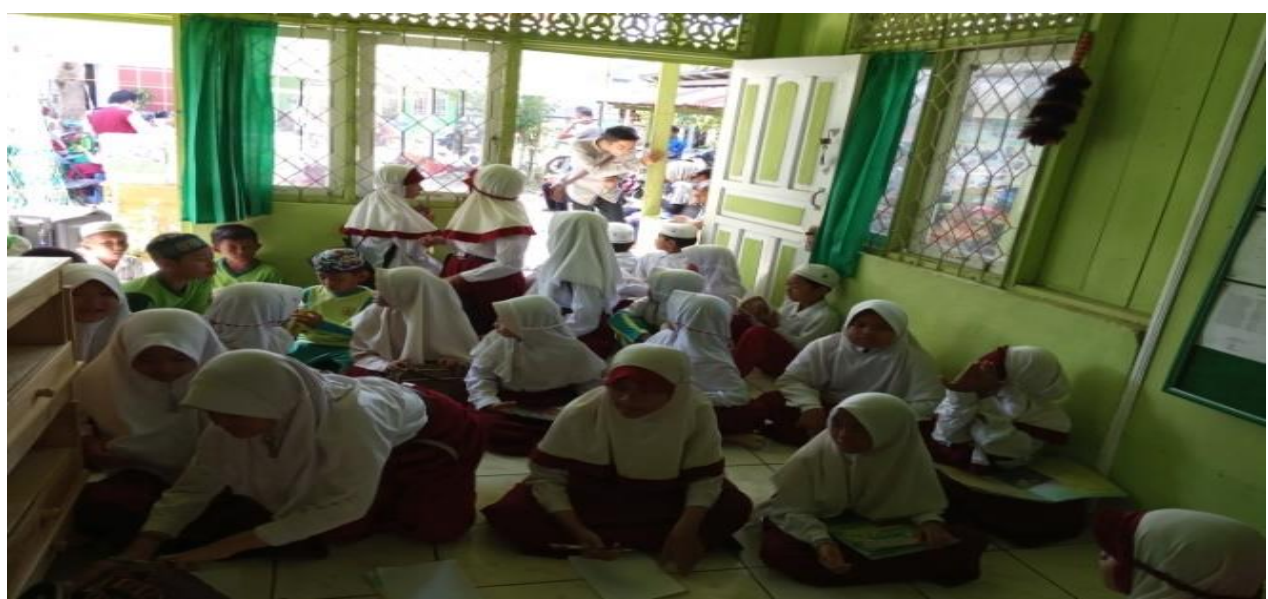

Gambar 4: Siswa Mempersiapkan Diri untun Menunggu Giliran Lomba Bercerita 


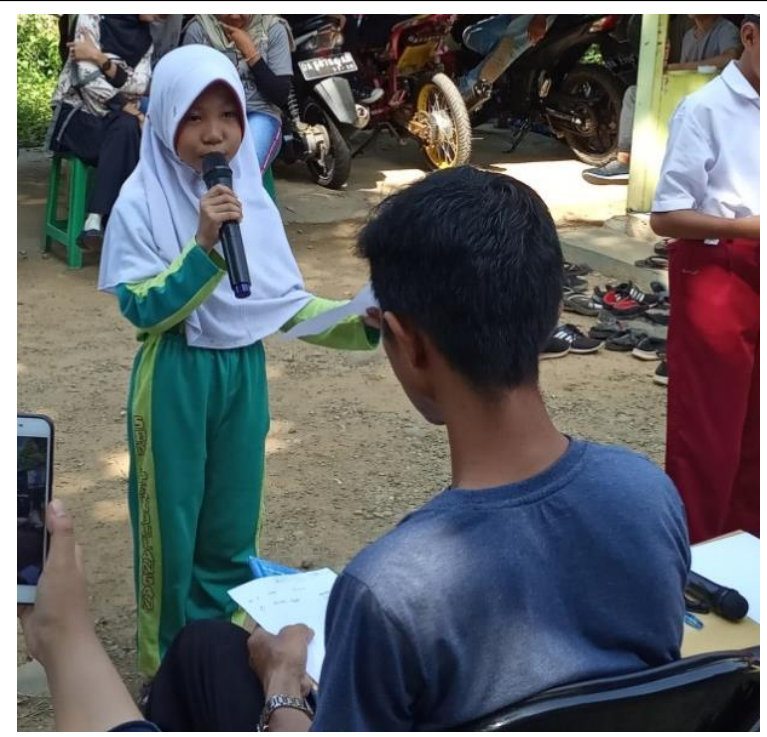

Gambar 5: Lomba Membaca Puisi

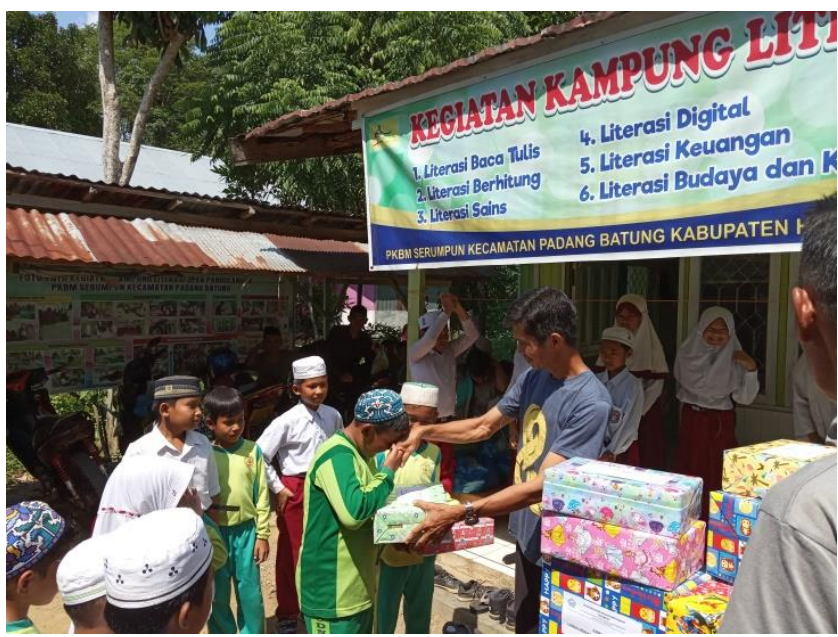

Gambar 6: Penyerahan Hadiah Lomba

Pelaksanaan program Kampung Literasi Desa Pandulangan bukan tanpa hambatan. Terdapat beberapa kendala yang dihadapi oleh pengelola seperti yang disampaikan oleh Akhmad Saidi, S.Pd. MM bahwa faktor penghambat program Kampung Literasi ini adalah hanya sedikit siswa yang termotivasi untuk benar-benar membaca, padahal buku yang disediakan sudah beragam dan tempat dibuka setiap hari. Hal ini seperti yang didapat oleh Kurniawan, dkk yang meneliti tentang problematika guru dalam melaksanakan program literasi di SD.(Kurniawan et al., 2019) Rendahnya motivasi sebagian siswa bisa dilihat bahwa siswa datang hanya untuk bermain atau berbicara dengan kawan-kawannya, bukan tujuan untuk membaca.

Selain itu, menurut beliau juga bahwa ruangan yang masih berukuran $8 \times 8$ Meter masih kurang luas untuk menampung orang yang datang untuk membaca. Ditambah lagi bahwa ruangan tidak dilengkapi dengan kursi dan meja untuk kenyamanan 
membaca. Padahal berdasarkan penelitian Wulandari bahwa ketersdiaan meja dan kursi merupakan salah satu hal yang membuat para membaca merasa nyaman. (Wulandari, 2012) Untuk mengatasi hal ini, pengelola mengizinkan kepada pengunjung untuk membawa buku dan membacanya di halaman sekitar.

Salah satu faktor lain yang menjadi penghambat pelaksanaan Program Kampung Literasi adalah kondisi cuaca khususnya ketika musim hujan. Musim hujan cenderung membuat akses masuk ke dalam desa menjadi bermasalah karena kondisi jalan yang menjadi becek sehingga mengurangi antusias siswa dalam mengunjungi lokasi.

Keluar dari permasalahan pelaksanaan, program Kampung Literasi Desa Pandulangan juga mendapat support baik berupa materi maupun non-materi. Menurut Akhmad Saidi, S.Pd. MM bahwa dukungan Dinas Perpustakaan dan Kearsipan Kabupaten Hulu Sungai Selatan selama ini sangat membantu pelaksanaan program karena pengadaan bahan bacaan yang bervariasi dan menarik bagi siswa. Ditambah lagi fasilitas untuk pengelola diantaranya berupa alat transportasi bahan bacaan, komputer, TV, dan DVD yang digunakan untuk memutar video pembelajaran.

Adapun jenis buku yang ada di Kampung Literasi berupa buku paket pelajaran seperti Mari Berhitung, Mari Membaca, Mengenal Tanda Baca, Mengenal Huruf Besar dan Huruf Kecil, Merangkai Kata. Selain itu juga ada buku cerita, dongeng, serta buku tentang budidaya pertanian, kreasi souvenir, bank sampah dan sebagainya. Hal ini sependapat dengan Fajrianti Ali yang menyatakan bahwa kesediaan bahan bacaan atau koleksi buku menjadi hal yang terpenting dalam penguatan budaya literasi, semakin banyak buku yang dimiliki maka akan membuat penguatan budaya literasi semakin bertambah. (Fajrianti, 2017)

Partisipasi masyarakat sekitar dalam mengembangkan Kampung Literasi Desa Pandulangan juga sangat mendukung. Hal ini terlihat di mana masyarakat mendorong putera-puteri mereka untuk mengunjungi dan membaca di sana. Dukungan dari masyarakat juga terlihat ketika pengelola mengadakan seperti lomba maupun gotong royong dalam membersihkan lokasi Kampung literasi.

Kampung Literasi merupakan model pembelajaran non-formal yang komprehensif. Kampung Literasi diharapkan bisa menjadi poros pendidikan nonformal masyarakat yang tidak hanya mengajarkan membaca, menulis dan berhitung (calistung), namun bisa menjadi salah satu solusi untuk mengatasi masalah rendahnya pengetahuan dan minat baca.

\section{CONCLUSIONS}

Berdasarkan hasil penelitian dan pembahasan yang mengacu pada rumusan masalah, diperoleh kesimpulan bahwa pelaksanaan Program Kampung Literasi dalam meningkatkan minat baca siswa sekolah dasar Desa Pandulangan berdasarkan tahap perencanaan dan pelaksanaan dapat dikatakan baik. Hal ini terlihat dari pengunjung yang datang dan antusias siswa ketika mengikuti lomba literasi. Kampung Literasi Desa Pandulangan dibuka setiap hari, dengan rincian hari Senin-Kamis dari pukul 08.00-12.00 WITA, hari Jum'at pukul 08.00-11.00 WITA, sedangkan hari Sabtu dan 
Minggu pukul 08.00-12.00 WITA tapi yang sering di dikunjungi hari jumat pagi karena pada hari tersebut ada kunjungan dari Dinas Perpustakaan dan Kearsipan Kabupaten Hulu Sungai Selatan berupa mobil Taman Bacaan Masyarakat (TBM) dan motor pintar membawa bahan bacaan yang berbeda-beda tiap minggu. Di desa pandulangan ada 2 buah sekolah dasar, yaitu SDN Pandulangan dan MIS Al-Husna Pandulangan. Kedua sekolah tersebut mengunjungi kampung literasi setiap Jumat secara bergantian dengan dua gelombang yaitu minggu pertama untuk kelas rendah dan minggu selanjutkan untuk kelas tinggi. Kampung Literasi juga mengadakan lomba yang memotivasi siswa dalam meningkatkan daya baca.

Faktor penghambat program Kampung Literasi Desa Pandulangan adalah masih terdapat sebagian siswa yang motivasi membacanya rendah, ukuran ruangan yang kurang luas, dan faktor cuaca. Sedangkan faktor pendukung adalah ketersediaan fasilitas untuk pemberkasan pengelola seperti komputer, bahan bacaan yang variatif, dukungan dari pemerintah dan masyarakat

\section{ACKNOWLEDGEMENTS}

Penulis mengucapkan terima kasih yang sebesar-besarnya kepada pemerintah Desa Pandulangan, pengelola Kampung Literasi, SDN Pandulangan, MIS Al-Husna, serta UNISKA Muhammad Arsyad Al Banjari atas dukungan dan bantuan dalam menyelesaikan penelitian ini.

\section{REFERENCES}

Ali, Fajrianti. (2017). Efektivitas Taman Baca Terhadap Penguatan Literasi Peserta Didik di SMA Negeri 10 Makassar. Makassar: Skripsi UIN Alauddin Makassar.

Ansari, Muhammad Iqbal. (2016). Rutinitas Keagamaan di Islamic Full Day School dalam Membentuk Rutinitas Keagamaan di Islamic Full Day School dalam Membentuk Karakter Religius Peserta Didik. Jurnal Muallimuna: Jurnal Madrasah Ibtidaiyah. Vol.1, No.2.

Ansari, Muhammad Iqbal dan Barsihanor. (2018). Sistem Karantina Tahfidzh 1 Hari untuk Anak Usia SD/MI di Rumah Tahfidzh Al-Haramain Kota Banjarmasin. Jurnal Al-Ibtida: Jurnal Pendidikan Guru MI. Vol 5 (2) : 205-220.

Amalia, Nadra. Deliati2 dan Mutia Febriyana. (2018). Melejitkan Daya Literasi melalui Pembelajaran Pantun. Kumpulan Jurnal Dosen Universitas Muhammadiyah Sumatera Utara.

Apriani, An-Nisa Apriani dan Yusinta Dwi Ariyani. (2015) Membangun Budaya Literasi Permulaan bagi Siswa SD Kelas Awal Melalui Pop Up Book. Yogyakarta: Repository Universitas PGRI Yogyakarta.

Kementerian Pendidikan dan Kebudayaan. 2017. Materi Pendukung Literasi Baca Tulis.Jakarta:Kementerian Pendidikan dan Kebudayaan. 
JIEES : Journal of Islamic Education at Elementary School Homepage : http://jiees.alkhoziny.ac.id/index.php/jeies Email : jiees@alkhoziny.ac.id
p-ISSN : 2723 -7184 ; e-ISSN : 2723-8148 JIEES, Vol. 1, No.2, Desember 2020 : 60-72

(C) 2020 JIEES : Journal of Islamic Education at Education School

Kementerian Pendidikan dan Kebudayaan. 2017. Paduan Penyelenggaran Program Kampung Literasi. Jakarta: Kementerian Pendidikan dan Kebudayaan.

Kurniawan, Agung Rimba, et.al. (2019). Problematika Guru dalam Melaksanakan Program Literasi di Kelas IV Sekolah Dasar. Edustream: : Jurnal Pendidikan Dasar. Vol.3, No.2.

Muin, Abdul dan Medya Ningsih. (2020, Maret 04). Bahan Bacaan yang di bawa ke Kampung Literasi. (Nor Saidah, Interviewer)

Patilimi, Hamid.2013. Metode Penelitian Kualitatif, Bandung: Alfabeta. Cet.4.

Permatasari, Andalusia N, et.al. (2017). Literasi Dini dengan Teknik Bercerita. Jurnal Family Edu UPI. Vol.3, No.1.

Portal Resmi. Hulu Sungai Selatan. (2020, Desember 06). Bupatu HSS Mencanangkan Gerakan Indonesia Membaca dan Kampung Literasi pada Desa Pandulangan. Dikutip dari Portal Resmi Hulu Sungai Selatan: https://hulusungaiselatankab.go.id. Diakses pada 23 Juli 2020 Pukul 20.15 WITA.

Puspen. Kemendagri. (2020, Februari 25). Atasi Rendahnya Minat Baca dengan Gerakan Literasi. Dikutip dari Puspen Kemendagri: https://perpusnas.go.id. Di akses pada tanggal 15 Maret 2020 Pukul 21.30 WITA.

Risalah, Ainur, et.al. (2020). Dampak Pandemi COVID-19 Terhadap Kegiatan Belajar Mengajar di MI/SD. JIEES : Journal of Islamic Education at Elementary School. Vol. 1, No. 1, Juni $2020: 10-16$.

Saidi, Ahmad. (2020, Maret 03). Meningkatkan Minat Baca Siswa Sekolah Dasar melalui Program Kampung Literasi Desa Pandulangan. (Nor Saidah, Interviewer)

Sugiyono. 2017. Metode Penelitian Kualitatif. Bandung: Alfabeta.

Wulandari, Wasis. (2012). Persepsi Pengguna Terhadap Layanan Ruang Baca Perpustakaan Umum. Journal-Unair.ac.id

Author (s)

Muhammad Iqbal Ansari (Corresponding Author)

Faculty of Islamic Studies,

Islamic University of Kalimantan Muhammad Arsyad Al Banjari Banjarmasin , Indonesia

Jl. Adiyaksa no.02, Kayu Tangi, Banjarmasin, 70123, Indonesia

Email: muhammadiqbalansari13@gmail.com

Nor Saidah

Faculty of Islamic Studies,

Islamic University of Kalimantan Muhammad Arsyad Al Banjari Banjarmasin , Indonesia

Jl. Adiyaksa no.02, Kayu Tangi, Banjarmasin, 70123, Indonesia

Email: iedahsaidah@gmail.com 
p-ISSN : 2723 -7184 ; e-ISSN : 2723-8148

Homepage : http://jiees.alkhoziny.ac.id/index.php/jeies

JIEES, Vol. 1, No.2, Desember 2020 : 60-72

Email : jiees@alkhoziny.ac.id

Jumiati

Faculty of Islamic Studies,

Islamic University of Kalimantan Muhammad Arsyad Al Banjari Banjarmasin , Indonesia

Jl. Adiyaksa no.02, Kayu Tangi, Banjarmasin, 70123, Indonesia

Email: jumiati.jumi88@gmail.com 